Bull. Chem. Soc. Ethiop. 2020, 34(1), 55-66.

ISSN 1011-3924

(C) 2020 Chemical Society of Ethiopia and The Authors

Printed in Ethiopia

DOI: https://dx.doi.org/10.4314/bcse.v34i1.5

\title{
MWCNTs/Ag-ZnO NANOCOMPOSITE FOR EFFICIENT PHOTOCATALYTIC DEGRADATION OF CONGO RED
}

\author{
Amogne W. Yibeltal ${ }^{1,2}$, Belete B. Beyene ${ }^{1,2}$, Shimelis Admassie ${ }^{3}$ and Abi M. Taddesse ${ }^{4 *}$ \\ ${ }^{1}$ Institute of Chemistry, Academia Sinica, No. 128, Sec. Academia Rd., Nangang, Taipei 115, \\ Taiwan \\ ${ }^{2}$ Department of Chemistry, Bahir Dar University, P. O. Box 79, Bahir Dar, Ethiopia \\ ${ }^{3}$ Material Science Program, Addis Ababa University, P.O. Box, 1176, Addis Ababa, Ethiopia \\ ${ }^{4}$ Department of Chemistry, Haramaya University, P.O. Box, 138, Dire Dawa, Ethiopia
}

(Received March 27, 2019; Revised January 2, 2020; Accepted February 17, 2020)

\begin{abstract}
Three nanomaterials namely, zinc oxide (ZC), silver-doped zinc oxide (AZ) and multi-walled carbon nanotubes coupled with silver doped zinc oxide nanocomposite (MWAZ) were synthesized, characterized and employed for photo degradation of an organic pollutant, congo red (CR). The photocatalytic activity study showed efficient degradation of CR upon irradiation with UV and visible light in the order of MWAZ $>$ AZ $>$ ZC $>$ Commercial $\mathrm{ZnO}$ (ZCO). Percentage photodegradation of $99 \%$ and a pseudo $1^{\text {st }}$ order rate constant of $2.3 \times 10^{-2}$ $\min ^{-1}$ were achieved by MWAZ as a catalyst under visible light irradiation, implying photosensitizing ability of MWCNTs and the capability of MWCNTs to hinder recombination of photogenerated holes and electrons. The control experiment in the dark condition gave only $7.9 \%$ of degradation efficiency and $5.56 \mathrm{x}$ $10^{-4} \mathrm{~min}^{-1}$ rate constant, implying the significant role of light source for catalytic degradation of CR.
\end{abstract}

KEY WORDS: Nanomaterials, Carbon nanotubes, Photocatalysis, Congo red, Visible light

\section{INTRODUCTION}

Due to chemical industry and agricultural revolution of $21^{\text {st }}$ century, wide varieties of organic pollutants have been discharged into water systems. The effluents from textile, chemical industries and agricultural runoffs contain several kinds of synthetic dyestuffs, which are highly toxic, environmentally unfriendly and harsh to aquatic life. Thus, it has been a great concern of the society, governmental and non-governmental organizations for decades. Studies showed that discharging a very small amount of dye into water is even highly visible and can affect aquatic life and food webs due to the carcinogenic and mutagenic effects of synthetic dyes [1]. In addition to the carcinogenic and mutagenic effects, synthetic dyes such as congo red (CR) (3,3'-([1,1'biphenyl]-4,4'-diyl)bis(4-aminonaphthalene-1-sulfonic acid) are known to cause an allergic reaction and metabolized to benzidine, a human carcinogen [2]. Because of its aromatic structure, $\mathrm{CR}$ has physico-chemical, thermal and optical stability and is difficult in biodegradation process [3].

To remove water pollutants, conventional physico-chemical wastewater treatment methods such as reverse osmosis, ion exchange, chemical precipitation and oxidation have been used for decades. However, applying these technologies has its own drawbacks due to high-energy consumptions, expensive synthetic resins and chemicals [4]. Hence, there need to be an easy, inexpensive and energy efficient technology. Photocatalytic degradation of water pollutants using $\mathrm{ZnO}$ appears to be the most interesting and has been a subject of research interest for decomposition of toxic compounds such as detergents, dyes, and pesticides to non-hazardous product. This is because $\mathrm{ZnO}$-based semiconductors are inexpensive, non-toxic, have high surface area and broad absorption spectra with high absorption coefficients [5]. In addition to this, they

*Corresponding author. E-mail: abi92003@yahoo.com

This work is licensed under the Creative Commons Attribution 4.0 International License 
exhibit tuneable properties, which can be modified by size reduction and doping, to afford facility for multi electron transfer process and extend their use without substantial loss of photocatalytic activity [6]. $\mathrm{ZnO}$ nanorods loaded on activated carbon (ZnO-NRs-AC) for adsorption of Bromocresol Green (BCG), Eosin Y (EY), azo-dyes and heavy metal ions accelerated by ultrasound was described $[7,8]$.

Following the development of improvement in optical properties of $\mathrm{ZnO}$, researchers have focused on hybrid materials of $\mathrm{ZnO}$ and carbon nanotubes (CNTs), due to unique internal structure, high surface area, low mass density, remarkable chemical stability, and electronic conductivity of CNTs [9]. Thus, CNTs enhance photosensitization behaviour of $\mathrm{ZnO}$ and hinders the recombination of electrons and holes. Moreover, they have a large surface area, and can act as a dispersing agent that prevents $\mathrm{ZnO}$ nanoparticles from agglomerating, which results in higher active surface area for the resultant hybrid compared with the $\mathrm{ZnO}$ nanoparticles. Quite recently, CNTs have been widely employed to enhance the photocatalytic activity of $\mathrm{ZnO}$ [9]. However, using $\mathrm{ZnO}$ alone as photocatalyst has several drawbacks such as fast recombination rate of photogenerated electron-hole pair, low quantum yield in the photocatalytic reactions in aqueous solutions and photo corrosion which obstruct commercialization of the photocatalytic degradation process [10]. Though various modification techniques are reported in the literature to overcome the above problems, little was documented on multi walled carbon nanotubes (MWCNTs) coupled with metal doped zinc oxide [11-14]. Besides, the report made by these authors are different from the present work in terms of the nature of precursors employed for the host crystal, the type of precipitating agent employed, the radiation source (UV, Vis) or the order of manipulation of $\mathrm{ZnO}$ in forming the composite. For example, Kim et al. [14] used impregnation of silver in the matrix of MWCNTs/ZnO composite. In the present work, we employed co-precipitation technique to grow the silver-doped $\mathrm{ZnO}$ on the surface of MWCNTs. The as-synthesized materials such as zinc oxide (ZC), silver-doped zinc oxide (AZ) and multi-walled supported silver-doped zinc oxide (MWAZ) were employed for photocatalytic degradation of an organic pollutant (congo red) up on irradiation of UV and Visible light sources.

\section{EXPERIMENTAL}

\section{Chemicals}

Multi walled carbon nanotubes (Sigma-Aldrich $>90 \%$ carbon basis, DxL $110-170 \mathrm{~nm}$ x 5-9 $\mu \mathrm{m}$ ), zinc nitrate hexahydrate $\left(\mathrm{Zn}\left(\mathrm{NO}_{3}\right)_{2} \cdot 6 \mathrm{H}_{2} \mathrm{O}\right),>99.9 \%$, from Shanghai), sodium carbonate $\mathrm{Na}_{2} \mathrm{CO}_{3}$, $>99 \%$, Aldrich), ethanol $\left(\mathrm{C}_{2} \mathrm{H}_{5} \mathrm{OH}\right), 95 \%$, Merck), silver nitrate $\left(\mathrm{AgNO}_{3}, 99.8 \%\right.$, Unichem Reagent), sulfuric acid $\left(\mathrm{H}_{2} \mathrm{SO}_{4}, 98 \%\right.$, Mumbai, India), nitric acid $\left(\mathrm{HNO}_{3}, 69 \%\right.$, Mumbai, India), commercial zinc oxide $\left(\mathrm{ZnO}\right.$, min assay $99.0 \%, \mathrm{BDH}$, LR, England), methanol $\left(\mathrm{CH}_{3} \mathrm{OH}\right.$, aluminum oxide $\left(\mathrm{Al}_{2} \mathrm{O}_{3}\right)$, phosphate buffer solution, $0.5 \mathrm{M} \mathrm{H}_{2} \mathrm{SO}_{4}$ and congo red (CR) $\left[\mathrm{C}_{32} \mathrm{H}_{22} \mathrm{~N}_{6} \mathrm{Na}_{2} \mathrm{O}_{6} \mathrm{~S}_{2}\right.$; MW $696.66 \mathrm{~g} / \mathrm{mol}$ ); dye content 95\%, absorption maximum $500 \mathrm{~nm}$ at pH 6.0) were used.

\section{Synthesis of nanomaterials}

$\mathrm{ZnO}$ nanoparticles were synthesized by direct precipitation method. Zinc nitrate hexahydrate $\left[\mathrm{Zn}\left(\mathrm{NO}_{3}\right)_{2} \cdot 6 \mathrm{H}_{2} \mathrm{O}\right]$ and sodium carbonate $\left[\mathrm{Na}_{2} \mathrm{CO}_{3}\right]$ solutions were separately prepared by dissolving $40.0 \mathrm{~g}$ of $\left[\mathrm{Zn}\left(\mathrm{NO}_{3}\right)_{2} \cdot 6 \mathrm{H}_{2} \mathrm{O}\right]$ and $33.0 \mathrm{~g}$ of $\mathrm{Na}_{2} \mathrm{CO}_{3}$ in $100 \mathrm{~mL}$ of deionized water (DI water). The $\left[\mathrm{Zn}\left(\mathrm{NO}_{3}\right)_{2} 6 \mathrm{H}_{2} \mathrm{O}\right]$ solutions were slowly dropped into $\mathrm{Na}_{2} \mathrm{CO}_{3}$ solution and the mixture was stirred continuously for $2 \mathrm{~h}$. The precipitate formed from the reaction between the two solutions was allowed to settle down for $24 \mathrm{~h}$, filtered with $0.2 \mu \mathrm{m}$ membrane filter (whatman) and washed three times each with DI water and ethanol. The filtered/washed precipitate was dried at $100{ }^{\circ} \mathrm{C}$ to form the precursor for $\mathrm{ZnO}$. The precursor thus obtained, after drying, was calcined at $300{ }^{\circ} \mathrm{C}$ for $24 \mathrm{~h}$ in programmable furnace to get the nanosized $\mathrm{ZnO}$ particles [6]. The product was 
labeled as (ZC). $\mathrm{Ag}$ doped $\mathrm{ZnO}$ was prepared by the following method [3]. In a typical synthesis, $5 \mathrm{~mL}$ of $0.18 \mathrm{M} \mathrm{AgNO}_{3}$ solution was added into $5 \mathrm{~g}$ of calcined zinc oxide (ZC). The sample was agitated and heated at $110{ }^{\circ} \mathrm{C}$ for $30 \mathrm{~min}$. The powder was cooled at room temperature, calcined at $300{ }^{\circ} \mathrm{C}$ for $24 \mathrm{~h}$ and then grounded using agate mortar. The product obtained was labelled as silverdoped zinc oxide (AZ). Zinc nitrate hexahydrate and sodium carbonate solutions were separately prepared by dissolving $40.0 \mathrm{~g}$ of $\left(\mathrm{Zn}\left(\mathrm{NO}_{3}\right)_{2} \cdot 6 \mathrm{H}_{2} \mathrm{O}\right)$ and $33.0 \mathrm{~g}$ of $\mathrm{Na}_{2} \mathrm{CO}_{3}$ in $100 \mathrm{~mL}$ of DI water. The $\left[\mathrm{Zn}\left(\mathrm{NO}_{3}\right)_{2} \cdot 6 \mathrm{H}_{2} \mathrm{O}\right]$ solution was slowly dropped into $\mathrm{Na}_{2} \mathrm{CO}_{3}$ solution and $5 \mathrm{~mL}$ of $0.18 \mathrm{M}$ $\mathrm{AgNO}_{3}$ solution was added to the above solution, and $300 \mathrm{mg}$ of purified MWCNTs were added to the solution. The mixture was stirred continuously for $2 \mathrm{~h}$ with magnetic stirrer. The precipitate resulting from the reaction mixture was allowed to settle down and filtered with $0.2 \mu \mathrm{m}$ membrane filter (Whatman) and washed three times with DI water and ethanol. The filtered/washed precipitate was dried at $100{ }^{\circ} \mathrm{C}$. After drying, it was calcined at $300{ }^{\circ} \mathrm{C}$ for $24 \mathrm{~h}$ to form MWCNTs/Ag-ZnO nanocomposite. The product obtained was labeled as multi walled carbon nanotubes/silver-doped zinc oxide (MWAZ).

\section{Characterization of nanomaterials}

The structures of the as-synthesized nanomaterials was examined by powder X-ray diffraction (XRD) using X'Pert Pro PANalytical equipped with an X-ray source of a $\mathrm{CuK} \alpha$ radiation (wavelength of $0.15406 \mathrm{~nm}$ ) at step scan rate of 0.02 (step time: $1 \mathrm{~s} ; 2 \theta$ range: $5.0-90.4^{\circ}$ ). Sizes of the ternary oxide particles were calculated by Debye Scherrer equation. The morphology and particle size distribution of the solids were determined by scanning electron microscopy (SEM) using a Hitachi TM1000 with EDX detector. UV-Vis absorption was measured using SP65 spectrophotometer at a scanning range from 200-800 nm. FTIR (Spectrum 65 FTIR (Perkin Elmer) instrument and measurements were performed with pressed pellets $(\mathrm{KBr})$ made using Paraffin as diluent. About 5 to $10 \mathrm{mg}$ of sample was placed onto the face of a $\mathrm{KBr}$ plate, a small drop of paraffin was added as a diluent.

\section{Photocatalytic dye degradation study}

Photocatalytic activities were studied toward degradation of CR under dark, visible light and ultraviolet illumination. A $0.15 \mathrm{~g}$ of photocatalyst powder and $100 \mathrm{~mL}$ of aqueous solution of CR $\left(15 \mathrm{mg} \mathrm{L}^{-1}\right)$ was taken into the reactor tube. The suspension was stirred in dark for $30 \mathrm{~min}$ to obtain adsorption/desorption equilibrium before irradiating the dye in the reactor [15] (Xu, 2010). The UV lamp (Philips) that predominantly emit at $354 \mathrm{~nm}$ with the definite power of $12 \mathrm{~W}, 230 \mathrm{~V}$ and $50 \mathrm{~Hz}$ frequency was employed as UV source; and tungsten lamp (Torch) with $550 \mathrm{~nm}$, definite power of $40 \mathrm{~W}, 220 \mathrm{~V}, 0.18 \mathrm{~A}$ and $50 \mathrm{~Hz}$ frequency was employed as visible source, and positioned parallel to the reactor. The distance between the top of reactor and lamp was $9 \mathrm{~cm}$. A 10 $\mathrm{mL}$ of the sample was withdrawn every 20 min interval. The suspension was centrifuged at 3000 rpm for 5-7 min and filtered to remove the catalyst particles before measuring absorbance. The absorbance of $\mathrm{CR}$ solution was determined at wavelength of $500 \mathrm{~nm}$ and the percentage degradation of CR was calculated using equation 1 [16].

$\%$ Degrdation $=\frac{A_{0}-A_{t}}{A_{0}} \times 100$

where $\mathrm{A}_{\mathrm{o}}$ is absorbance of dye at initial stage and $\mathrm{A}_{t}$ is at a time " $\mathrm{t}$ ".

\section{RESULTS AND DISCUSSION}

The characteristic XRD patterns of nanomaterials are shown in Figure 1. The diffraction peaks at scattering angles (20) around 30.50, 32.25, 35.45, 36.50, 50.10, 60.00 and 63.50 correspond to the 
reflection from (100), (002) (101) (102) (110) (103) and (112) crystal planes, respectively suggesting wurtzite structure of $\mathrm{ZnO}$ [17]. The characteristic peaks in Figure 1 have broadened and are in accordance with the zincite phase of $\mathrm{ZnO}$, indicating the doped material does not influence the crystalline structure [18]. Furthermore, it could be seen that the diffraction peaks are intensive, implying a good crystalline nature of the as-synthesized $\mathrm{ZnO}$ product. The peaks, which appeared in $\mathrm{AZ}$ and MWAZ, are somewhat broader than those for pure $\mathrm{ZnO}$. This suggests that $\mathrm{Ag}$ and MWCNT are incorporated into $\mathrm{ZnO}$ lattice, respectively. Diffraction peaks of $\mathrm{ZnO}$ (AW1) at $2 \theta$ values of $31.66,34.22,36.25,47.86,56.51,62.66,66.37,67.92$ and 69.26 corresponding to the crystal planes of (100), (002), (101), (102), (110), (103), (200), (112), and (201) confirm the formation of hexagonal wurtzite structure of pure $\mathrm{ZnO}$ [96-900-4179]. The diffraction pattern of $\mathrm{Ag}-\mathrm{ZnO}$ (AW2) reveals the presence of all peaks attributed to hexagonal wurtzite structure of $\mathrm{ZnO}$ above. No peak was attributable to silver perhaps due to small amount $(<3 \%)$ of dopant introduced into the $\mathrm{ZnO}$ matrix. However, additional peaks have been observed at $2 \theta$ values between 6.93 and 28.70. The literature values indicate presence of several peaks in the range shown above attributable to either $\mathrm{Zn}(\mathrm{OH})_{2}$ or $\mathrm{ZnO}$ [17].

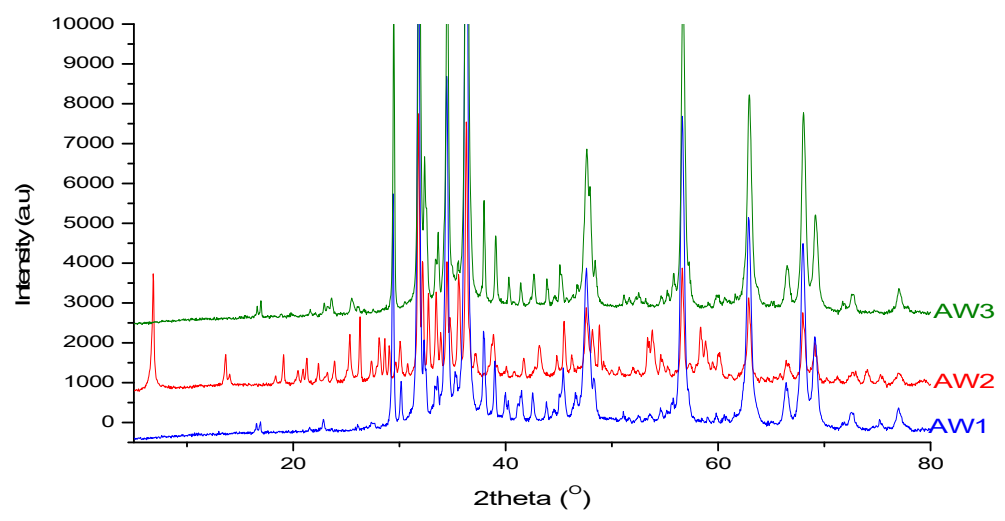

Figure 1. XRD patterns of $\mathrm{ZnO}(\mathrm{AW} 1), \mathrm{Ag}-\mathrm{ZnO}$ (AW2) and MWCNT/Ag-ZnO (AW3).

There has been a gap between time of characterization and photocatalytic study. The characterization was done long after the photocatalytic study. Formation of $\mathrm{Zn}(\mathrm{OH})_{2}$ as the result of such long term interaction between the $\mathrm{ZnO}$ powder and adsorbed external water might happen or perhaps some of $\mathrm{Zn}(\mathrm{OH})_{2}$ might have not been converted to $\mathrm{ZnO}$ due to calcinations. On the other hand, the XRD patterns of MWCNTs/Ag-ZnO(AW3) showed diffraction patterns attributable to the host crystal $\mathrm{ZnO}$ [96-901-1663]. The additional diffraction peak observed at $2 \theta$ value of 25.49 (002) could be accounted for the presence of MWCNTs. Similar result has been made by [19] for ZnO embedded MWCNTs they synthesized. In the sample AW3, no peak was attributable to silver as the result of small percentage $(<3 \%)$ of the dopant employed in this study. The average crystallite size of the as-synthesized photocatalysts can be calculated using the DebyeScherer equation [20]:

$D=\frac{0.9 \lambda}{\beta \operatorname{Cos} \theta}$

where $\mathrm{D}$ is the average crystallite size, $\lambda$ is the wavelength of the $\mathrm{X}$-ray $=0.15406 \mathrm{~nm}$ for Cu target $\mathrm{K} \alpha$ radiation, $\beta$ is the full width of half-maximum (FWHM) in radian, and $\theta$ is the Bragg diffraction angle. The calculated average crystallite sizes (D) of the photocatalysts are given in Table 1. Order of average crystallite size (D) of as-synthesized photocatalysts is: AZ $<$ MWAZ $<$ ZC. 
Table 1. Average crystallite size (D) of as-synthesized photocatalyst.

\begin{tabular}{|l|l|l|l|}
\hline Sample & $2 \theta$ (Degree) & $\beta$ (Radian) & $\mathrm{D}(\mathrm{nm})$ \\
\hline ZC & 36.601 & 0.0060 & 32.99 \\
\hline AZ & 36.496 & 0.0046 & 25.27 \\
\hline MWAZ & 36.503 & 0.0056 & 27.24 \\
\hline
\end{tabular}

\section{SEM-EDX analysis}

The SEM micrographs for the MWCNTs/Ag-ZnO nanocompsoite exhibited aggregate of nanoparticles with no distinct morphology Figure 2. The presence of silver is noted here as seen in the EDX spectra of the nanocomposite. The percentage composition of zinc ranged from 87.3 to 91.5 and silver from 0.3 to 2.4 showing the relatively narrower composition of zinc and silver in the nanocompsoite. A certain amount of sulphur was detected as an impurity possibly from the residual sulfuric acid used to purify the MWCNTs.
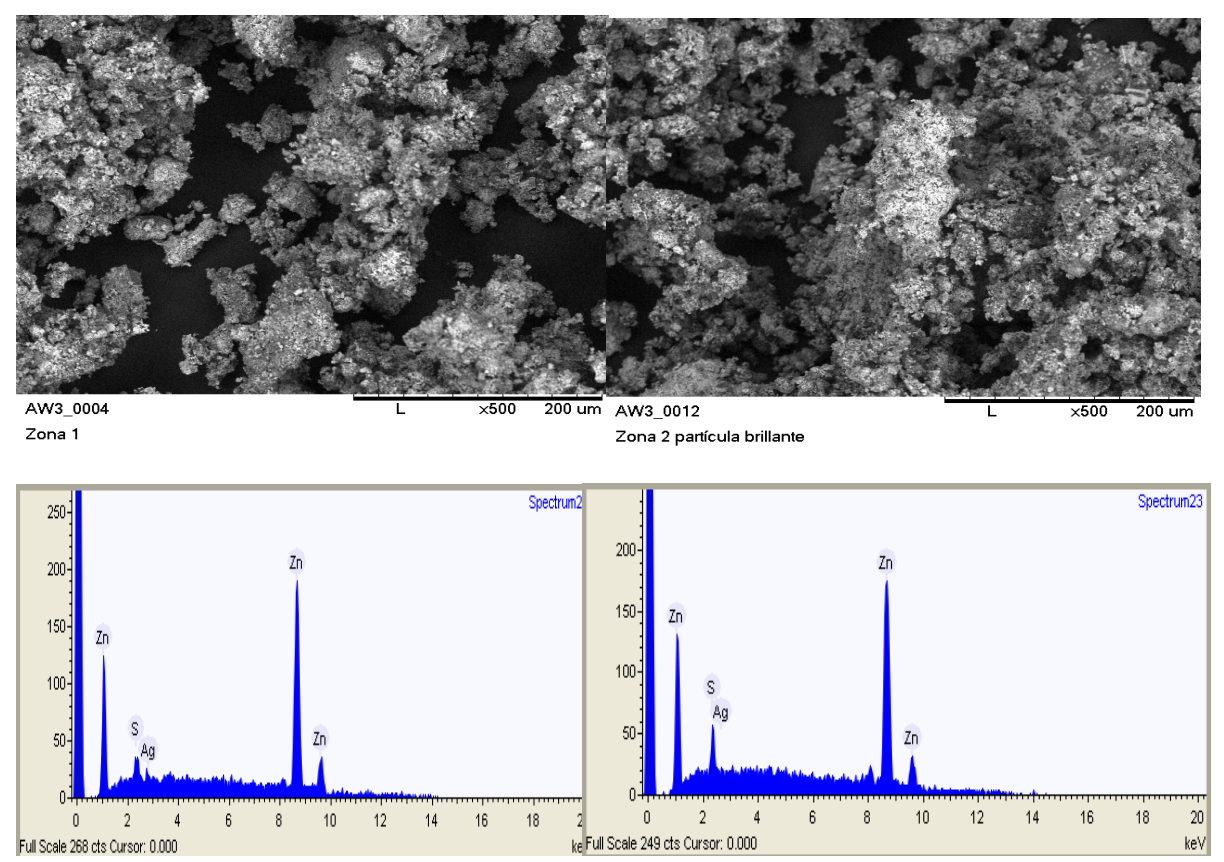

Figure 2. SEM-EDX micrographs of MWCNTs/Ag-ZnO nanocomposite.

\section{UV-Vis analysis}

UV-Vis absorption and FTIR spectra of nanomaterials is shown in Figure 3 and Table 2. The ZC showed $\lambda_{\max }$ of $376 \mathrm{~nm}$, corresponding to intrinsic absorption behavior of $\mathrm{ZnO}$ and it is in good agreement with the reported result [21]. This peak is red shifted, as compared to the bulk exciton, which is due to the size effect of the nanostructures. The AZ showed red shift in absorption compared to ZC, may be due to creation of localized energy levels by doped Ag in the band gap of $\mathrm{ZnO}$ [22]. The $\lambda \max$ of the catalyst MWAZ obviously shifted further to the visible region compared to $\mathrm{ZC}$ and $\mathrm{AZ}$, with intense visible-light absorption and broadening of the band. This 
can be attributed to the fact that MWCNTs enhance photosensitization of zinc oxide nanoparticles due to their larger surface area. Moreover, the presence of silver contributes the narrowing of band gap of nanomaterial. Band gap energy $(\mathrm{Eg})$ of the as-synthesized nanomaterials was obtained using equation 3 [23].

$\mathrm{E}_{\mathrm{g}}(\mathrm{eV})=\frac{1240}{\lambda}$

where, $E_{g}$ is band gap energy in electron volts and $\lambda$ is wavelength $(\mathrm{nm})$ corresponding to absorption maxima. The $\mathrm{E}_{\mathrm{g}}$ values of nanomaterials are shown in Table 2.

\section{FTIR analysis}

The FTIR spectra of $\mathrm{ZnO}(\mathrm{A}), \mathrm{Ag}-\mathrm{ZnO}(\mathrm{B})$ and MWCNTs/Ag-ZnO (C) are shown in Figure 3a. The peaks exhibited by the as-synthesized materials appeared to vary with the syntheses methods employed. For example, we followed precipitation technique for the preparation of $\mathrm{ZnO}$ and MWCNTs/Ag-ZnO. As the result, the peaks obtained are more or less similar. The presence of peaks related to carboxylic [14] and carbonates [24] is evidenced in both cases. In the synthesis of $\mathrm{Ag}-\mathrm{ZnO}$, we followed impregnation of silver nitrate on the as-synthesized $\mathrm{ZnO}$ nanparticles. The calcination of this composite facilitated the removal of residual carbonates, that might come from the $\mathrm{ZnO}$ precursor $\left[\mathrm{Zn}\left(\mathrm{CO}_{3}\right)_{2}(\mathrm{OH})_{6}\right]$ [24] that might sustain during the synthesis of $\mathrm{ZnO}$ nanoparticles. The peaks ranging from 3439 to $3449 \mathrm{~cm}^{-1}$ may be due to O-H stretching mode of adsorbed water molecules [25] and indicates the existence of small amount of water adsorbed to the nanomaterials. The peak around $2924 \mathrm{~cm}^{-1}$ and $2854 \mathrm{~cm}^{-1}$ are assigned to residual organic components with asymmetric and symmetric $\mathrm{C}-\mathrm{H}$ stretch-mode frequencies, respectively. The peak at $2492 \mathrm{~cm}^{-1}$ and $2427 \mathrm{~cm}^{-1}$ arises from the absorption of atmospheric $\mathrm{CO}_{2}$ on the metallic cations. The peak at $1775 \mathrm{~cm}^{-1}$ and $1620 \mathrm{~cm}^{-1}$ could be associated with the bending vibrations of water molecules. Bands at $1441 \mathrm{~cm}^{-1}$ and $1384 \mathrm{~cm}^{-1}$ corresponds to asymmetric stretching of $\mathrm{C}=\mathrm{O}$ bonds of the carboxylate ions which might remain adsorbed on the surface of $\mathrm{ZnO}$ during calcination. The peak at $881 \mathrm{~cm}^{-1}, 837 \mathrm{~cm}^{-1}$ and $701 \mathrm{~cm}^{-1}$ are due to $\mathrm{O}-\mathrm{C}-\mathrm{O}$ stretching vibrations of the monodentate carbonate species originated from $\mathrm{CO}_{2}$, which may come from the carbonate salt adsorbed from the atmosphere. The peak appearing at about $438 \mathrm{~cm}^{-1}$ is assigned to the metal - oxygen $(\mathrm{Zn}-\mathrm{O})$ stretching mode [26].

\section{Photocatalytic degradation study}

Under properly optimized condition against $\mathrm{pH}$, initial dye concentration and photocatalyst load values, the photocatalytic activities of nanomaterials were investigated for the degradation of $\mathrm{CR}$ solution in the dark, under UV and visible radiation. The \% adsorptions of CR was used as reference as zero minute irradiations [27]. Plots of \% adsorption as a function of time in the dark and under UV irradiation are given in Figure 4. In the dark, only insignificant percentage degradation of $\mathrm{CR}$ is observed for all nanomaterials with $\mathrm{ZCO}, \mathrm{ZC}, \mathrm{AZ}$, and MWAZ \% degradation values of 4.2, 7.9, 3.6 and 7.9, respectively, after $180 \mathrm{~min}$, indicating light has a role in degradation process. However, up on irradiation with UV light source, the photocatalytic activity of nanomaterials toward degradation of CR was enhanced, with the percentage photodegradation of CR under UV irradiations after $180 \mathrm{~min}$ is $21.1,55.7,66.6$, and 81.6 for $\mathrm{ZCO}, \mathrm{ZC}, \mathrm{AZ}$, and MWAZ, respectively. 

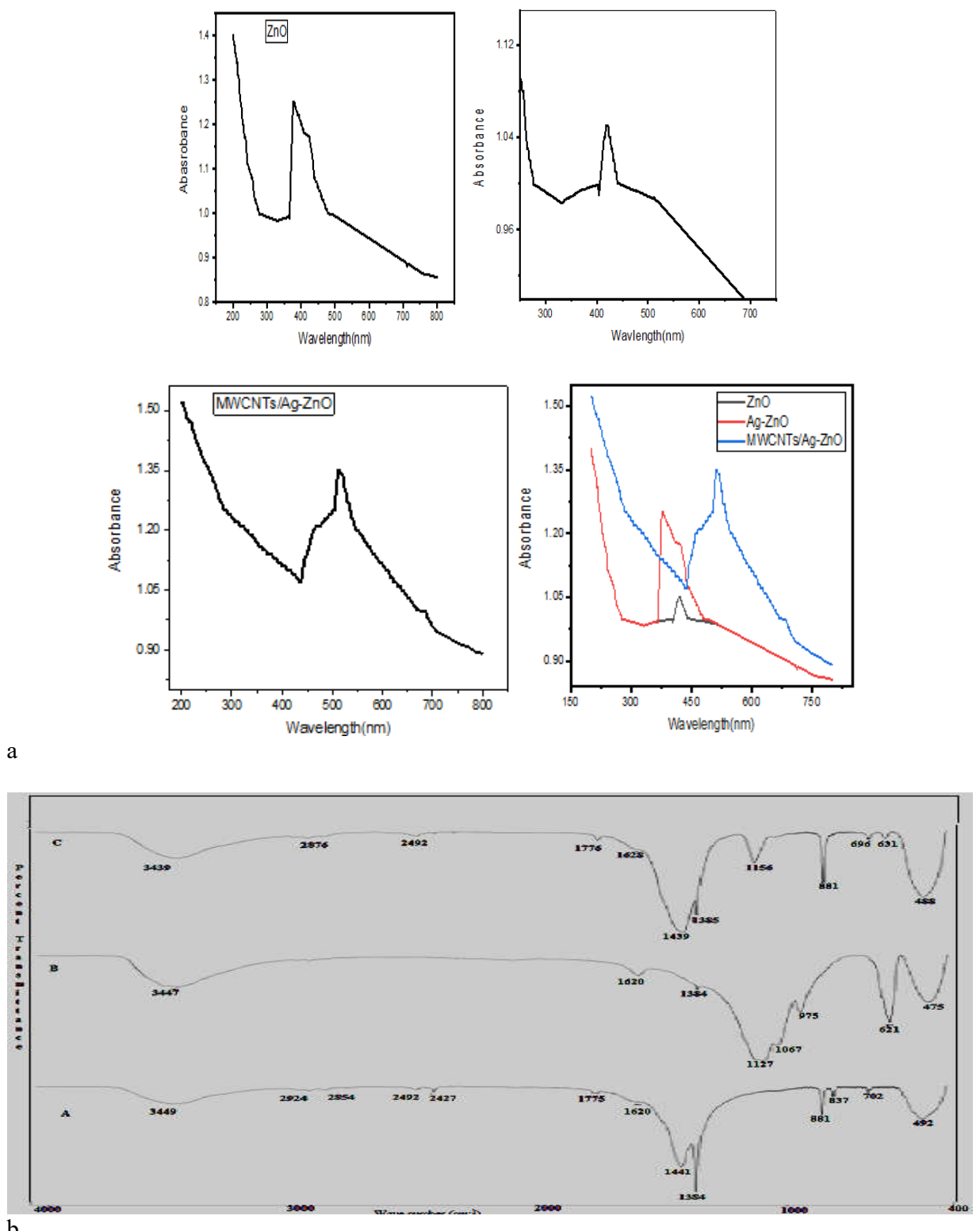

Figure 3. (a) UV-Visible absorption spectra of $\mathrm{ZnO}, \mathrm{Ag}-\mathrm{ZnO}, \mathrm{MWCNTs} / \mathrm{Ag}-\mathrm{ZnO}$ (independent) and combined and (b) FTIR spectra of ZnO (A), Ag-ZnO (B) and MWCNT/Ag-ZnO (C).

The photocatalytic degradation experiment of CR was also performed by irradiating with visible light source as shown in Figure 5 with the percentage photodegradation values of 33.6, 
67.0, 77.4, and 98.7, for ZCO, ZC, AZ, and MWAZ, respectively. Interestingly, MWAZ showed super catalytic activity and efficiency toward photodegradation of CR under visible light. The origin of the difference in photocatalytic activity of the doped and undoped $\mathrm{ZnO}$ catalysts might be explained as follows. Regardless of the magnetic and thermal properties, one can consider that all photocatalyst materials are assumed to be comprised of mainly two interlinked parts: the photosensitization part and the catalysis part [18]. The photosensitizing part is intrinsically concerned with the interaction of the semiconducting materials with light, for example, absorption of light, band gap, formation of electrons-holes, their dynamics and surface trapping, whereas the catalysis part includes surface area, surface reactivity, radical formation and the heterogeneous interaction of the chemical species with catalyst surface. More importantly, the better the crystalline quality and the lower the band gap, the more improvement on the photo part leading to the higher visible light reactivity of the catalysts. On the other hand, the higher the surface area, the higher will be the reactivity. Fundamentally, photocatalysis is an interfacial reaction and a higher specific surface area of the material, of course, produces a greater number of accessible active sites, thereby yielding an enhanced reactivity. Moreover, the photocatalytic activity of any semiconductor photocatalyst is, in fact, the result of a compromise and combination of these two structural parameters. Keeping this principle in mind, among photocatalysts studied, ZCO is found to have lowest photoactivity under both UV and visible irradiations.

Table 2. Absorbance, wavelengths and band gaps energies of as-synthesized photo-catalysts.

\begin{tabular}{|l|l|l|l|}
\hline Samples & Absorbance & Absorption maxima $(\mathrm{nm})$ & Band gap $(\mathrm{Eg})(\mathrm{eV})$ \\
\hline ZC & 1.25 & 376 & 3.29 \\
\hline AZ & 1.05 & 420 & 2.95 \\
\hline MWAZ & 1.34 & 510 & 2.43 \\
\hline
\end{tabular}
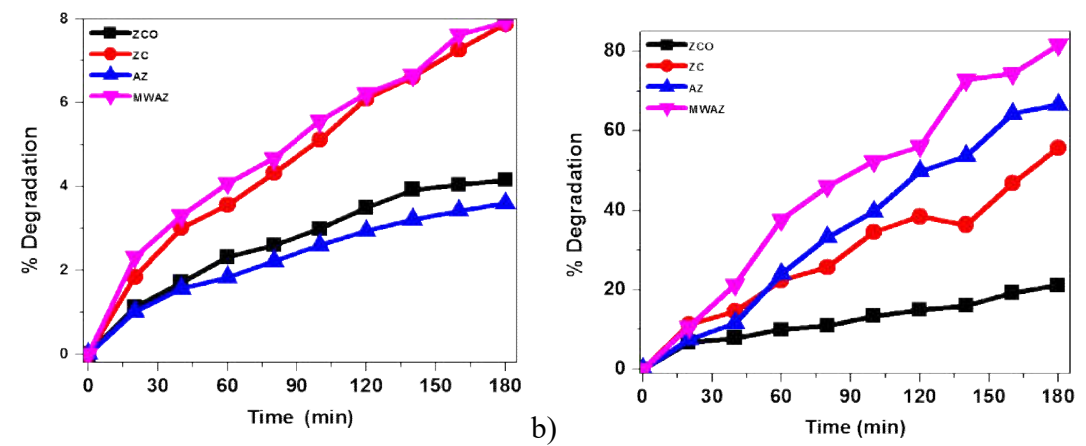

a)

Figure 4. Percentage degradation of CR vs time a) in the dark; b) under UV irradiation with photocatalyst loading of $150 \mathrm{mg} \mathrm{L}^{-1}, \mathrm{pH}=6$ and initial dye concentration $=15 \mathrm{mg} \mathrm{L}^{-1}$ ).

This may be due to its small specific surface area or higher band gap. AZ shows higher photocatalytic activity than ZC under both visible and UV light irradiations. This may be due to the ability of $\mathrm{Ag}$ to trap electrons from $\mathrm{CB}$ [28]. This process reduces the $\mathrm{e}^{-}$and $\mathrm{h}^{+}$ recombination at $\mathrm{ZnO}$ surface. Therefore, a more effective electron and hole transfer occurs to the electron acceptors and electron donors, respectively adsorbed on the surface of the particle than in the case of ZC. Another possible reason for the better photocatalytic activity of AZ is that doping of silver leads to red shift by narrowing the band gap energy in the visible region 
(Table 2), which in turn enhances its photocatalytic activity [12-14]. Photocatalytic efficiency is a function of oxygen vacancies and defects in $\mathrm{ZnO}$. These vacancies and defects inhibit the $\mathrm{e}^{-}-\mathrm{h}^{+}$ recombination process by capturing photo-induced electrons and holes and hence improve photoactivity. Moreover, oxygen vacancies also promote the adsorption of $\mathrm{O}_{2}$ which is converted into superoxide radicals $\left(\mathrm{O}_{2}{ }^{-}\right)$by interacting with photo-induced electron. These ${ }^{\circ} \mathrm{O}_{2}{ }^{-}$ radicals are active to promote the oxidation of organic substances by forming other radicals such as ${ }^{\circ} \mathrm{OH}$ and $\mathrm{HO}_{2}{ }^{\circ}$ [27]. In case of $\mathrm{AZ}$ under UV irradiations, silver can entrap the photogenerated electrons thereby decreasing probability of electron hole recombination, and hence increase photocatalytic activity [29]. The photocatalytic activity of MWAZ is large compared to other as-synthesized photocatalysts under study in both UV and visible irradiations. This is due to synergetic effect of electron trapping by Ag doping and the ability of MWCNTs as photosensitizers for semiconductor $\mathrm{ZnO}$, Moreover, due to their large surface area MWCNT could serve as a dispersing agent [14] preventing $\mathrm{ZnO}$ nanoparticles from agglomeration, resulting in higher active surface area of the nanocomposite catalyst compared with the $\mathrm{ZnO}$ nanoparticles. As a result, the photocatalytic degradation of the CR is widely enhanced [9].
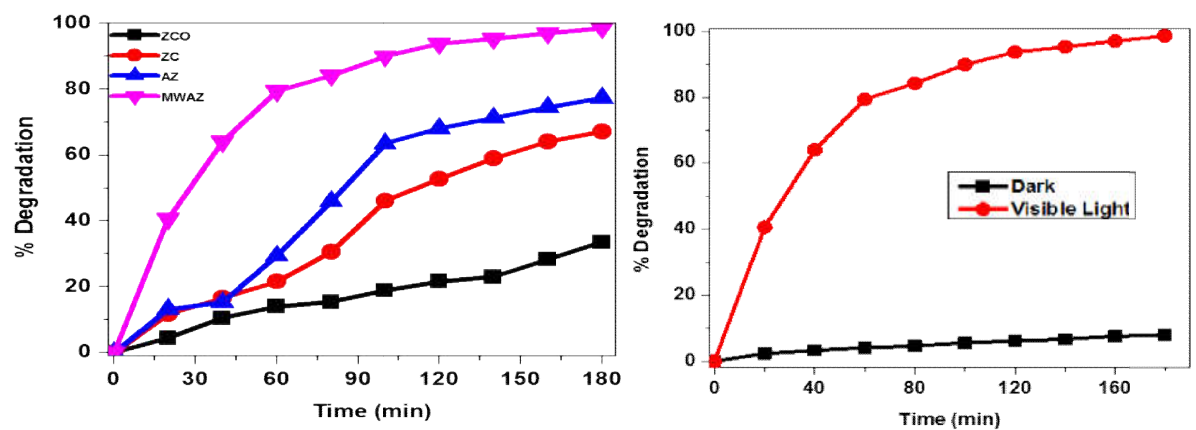

Figure 5. \% degradation of CR vs time a) visible; b) for MWAZ under visible irradiation vs dark with photocatalyst load $=150 \mathrm{mg} \mathrm{L}^{-1}, \mathrm{pH}=6$ and initial dye concentration $=15 \mathrm{mg} \mathrm{L}^{-1}$ ).

Photocatalytic mechanism

The mechanistic approach for photodegradation of CR by as-synthesized nanomaterials is proposed based on literature reports and the observed photocatalytic activity differences among the photocatalysts. In basic terminology, the enhancement in photocatalytic activity is attributed to the outstanding electrical property of MWCNTs and the defects in the ZnO crystals caused by Agdoping [12]. When silver replaces the zinc site of $\mathrm{ZnO}$ lattice or inserts into the $\mathrm{Zn}$ interstitial, the lattice of $\mathrm{ZnO}$ is distorted and forms oxygen vacancies and zinc vacancies, resulting in creating intermediate energy gap in $\mathrm{ZnO}$ crystal [12]. The intermediate energy gap can promote the absorption of photons and create electron-hole pairs. Under light irradiation, the electrons (e $\left.\mathrm{e}^{-}\right)$in the valence band $(\mathrm{VB})$ of $\mathrm{ZnO}$ are excited to the conduction band $(\mathrm{CB})$, leaving holes $\left(\mathrm{h}^{+}\right)$in the VB. MWCNTs have a large electron-storage capacity (one electron for every 32 carbon atoms) [30], and it is easy to capture photogenerated electrons (e) from the $\mathrm{CB}$ of $\mathrm{ZnO}$, hindering the recombination of electron-hole pairs. The photogenerated holes $\left(\mathrm{h}^{+}\right)$can migrate to the $\mathrm{ZnO}$ surface easily, and directly oxidize the adsorbed $\mathrm{CR}$ into $\mathrm{CO}_{2}$ and $\mathrm{H}_{2} \mathrm{O}$. Simultaneously, more photogenerated holes can react with adsorbed water to form hydroxyl radical (HO), which is available to promote the decomposition of CR. Furthermore, the oxygen adsorbed on the surface of $\mathrm{ZnO}$ may accept $\mathrm{e}^{-}$and form $\mathrm{O}_{2}^{-}$, which also leads to the formation of $\mathrm{HO}$, resulting in degrading the CR. The mechanistic process of electron transport in MWCNTs/ZnO hybrids and photocatalytic degradation are shown in Figure 6a. 
(a)

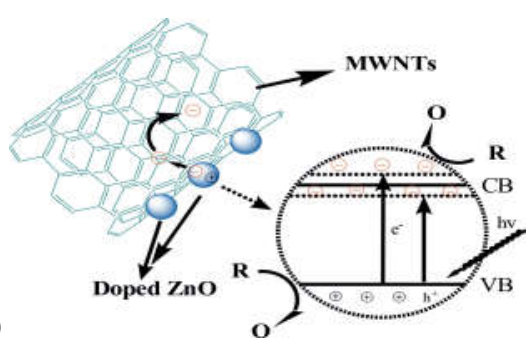

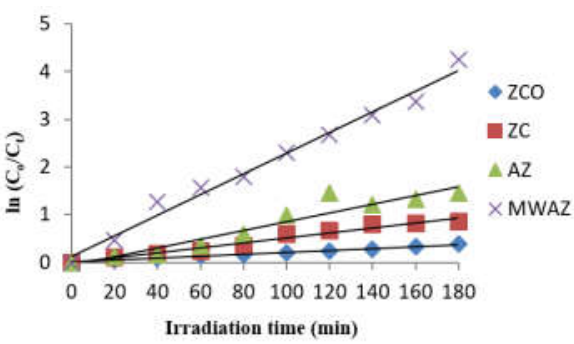

(b)
Irradiation time (min)

Figure 6. (a) The complete scheme of electron transfer in MWNTs/Ag-ZnO hybrid and (b) plot of $\ln \left(\mathrm{C}_{\mathrm{o}} / \mathrm{C}_{\mathrm{t}}\right)$ vs time for photocatalytic degradation of $\mathrm{CR}$ using photocatalysts under visible irradiation.

Kinetic studies of photocatalytic degradation of CR without irradiation and its photocatalytic degradation under UV and visible irradiations follows pseudo first-order reaction kinetics expressed by the equation:

$\ln \frac{c_{0}}{c_{t}}=k t$

where $\mathrm{k}$ is the reaction rate constant, $\mathrm{C}_{\mathrm{o}}$ is the initial concentration of aqueous $\mathrm{CR}$, and $\mathrm{C}_{\mathrm{t}}$ is the concentration of aqueous $C R$ at the reaction time $t$. The $\operatorname{lnC}_{\mathrm{o}} / \mathrm{C}_{\mathrm{t}}$ as a function of time $(\mathrm{t})$ is shown in Figures $6 \mathrm{~b}$. The adsorption rate constants for $\mathrm{CR}$ using $\mathrm{ZCO}, \mathrm{ZC}, \mathrm{AZ}, \mathrm{MWAZ}$ (without irradiation) are: $2.28 \times 10^{-4}, 4.28 \times 10^{-4}, 2.01 \times 10^{-4}$, and $5.56 \times 10^{-4} \mathrm{~min}^{-1}$, respectively. The rate constants for degradation of $\mathrm{CR}$, under UV irradiations, using ZCO, ZC, AZ, MWAZ photocatalysts are: $1.42 \times 10^{-3}, 3.96 \times 10^{-3}, 5.47 \times 10^{-3}, 6.54 \times 10^{-3} \mathrm{~min}^{-1}$, respectively, while under visible irradiation these values are: $2.15 \times 10^{-3}, 4.72 \times 10^{-3}, 8.08 \times 10^{-3}, 23.64 \times 10^{-3} \mathrm{~min}^{-1}$, respectively. In general, a fairly good correlation to the pseudo-first order reaction kinetics $\left(\mathrm{R}^{2} \geq\right.$ 0.912) was observed in the present work.

\section{CONCLUSION}

The $\mathrm{ZnO}$, Ag-doped $\mathrm{ZnO}$, MWCNTs/Ag-doped $\mathrm{ZnO}$ were synthesized and characterized using $\mathrm{X}$-ray diffraction (XRD), scanning electron microscopy (SEM-EDX), FTIR and UV-Vis spectrophotometer. The XRD results indicate that all the compositions of nanomaterials give pure hexagonal wurtzite crystalline structure. The optical band gap calculated using UV-visible absorption spectra was decreased from 3.29 to $2.43 \mathrm{eV}$. The MWCNTs/Ag-ZnO nanocomposite showed enhanced photocatalytic degradation of $\mathrm{CR}$ due to the electronic interaction of the carbon nanotubes and the metal oxide nanoparticles by transfer of electrons from the metal to the carbon nanotubes surface. The order of photocatalytic efficiency without radiation is: $\mathrm{MWAZ}>\mathrm{ZC}>\mathrm{ZCO}>\mathrm{AZ}$ whereas it is found that MWAZ $>\mathrm{AZ}>\mathrm{ZC}>\mathrm{ZCO}$ under both UV and visible irradiation. The percentage photodegradation of $99 \%$ and a pseudo 1 st order rate constant of $2.3 \times 10^{-2} \mathrm{~min}^{-1}$ is achieved by MWAZ as a catalyst under visible light irradiation. The control experiment in the dark condition gave only $7.9 \%$ of degradation efficiency and 5.56 x $10^{-4}$ min- rate constant, implying the significant role of light source for catalytic degradation of CR.

\section{ACKNOWLEDGEMENTS}

The authors would like to acknowledge the financial support received from Ministry of Education through the office of Postgraduate Program Directorate, and the HU grant via a 
project code (HURG-2016-03-02), Haramaya University. The support in characterizing our samples received from Instituto de Catalisis y Petroleoquimica, CSIC, is also highly acknowledged.

\section{REFERENCES}

1. Crini, G. Non-conventional low-cost adsorbents for dye removal. A review. Bioresour. Technol. 2006, 97, 1061-1085.

2. Sudipta, C.; Dae, S.; Min, W.; Seung, H. Enhanced adsorption of Congo red from aqueous solutions by chitosan hydrogel beads impregnated with cetyl trimethyl ammonium bromide. Bioresour. Technol. 2009, 100, 2803-2809.

3. Han, R.; Ding, D.; Xu, Y.; Zou, W.; Wang, Y.; Li, Y.; Zou, L. Use of rice husk for adsorption of Congo red from aqueous. Bioresour. Technol. 2008, 99, 2938-2946.

4. Annadurai, R.S.; Juang, P.S.; D.J. Lee,. Use of thermally treated waste biological sludge as dye absorbent. Adv. Environ. Res. 2003, 7, 739-744.

5. Chatterjee, D.; Shimanti, D. Visible light induced photocatalytic degradation of organic pollutants. J. Photochem. Photobiol. C: Photochem. Rev. 2005, 6, 186-205.

6. Chen, C.C.; Ping L.; Chun, H. L. Synthesis and characterization of nano-sized ZnO powders by direct precipitation method. J. Chem. Eng. 2008, 144, 509-513.

7. Arash, A.; Mehrorang, G.; Shaaker, H.; Alireza, G.; Ebrahim, A.D. Application of ZnO nanorods loaded on activated carbon for ultrasonic assisted dyes removal: Experimental design and derivative spectrophotometry method. Ultrason. Sonochem. 2017, 34, 1-12.

8. Ebrahim, A.D.; Mehrorang, G.; Arash, A. The performance of nanorods material as adsorbent for removal of azo dyes and heavy metal ions: Application of ultrasound wave, optimization and modeling. Ultrason. Sonochem. 2017, 34, 792-802.

9. Chen, C.S.; Xie, X.D.; Liu, T.G.; Lin, L.; Kuang, W.; Xie, J.C.; Lu, X.L.; Cao, S.Y. Multiwalled carbon nanotubes supported $\mathrm{Cu}$-doped $\mathrm{ZnO}$ nanoparticles and their optical property. J. Nanopart. Res. 2012, 14, 817.

10. Linsebigler, A.L.; Lu, G.; Yates, J.T. Photocatalysis on $\mathrm{TiO}_{2}$ surfaces: Principles, mechanisms, and selected results. Chem. Rev. 1995, 95, 735-758.

11. Chen, C.S.; Xie, X.D; Cao, S.Y.; Liu, T.G.; Lin, L.W.; Chen, X.H.; Liu, Q.C.; Kuang, J.C; Xiao, Y. Preparation and photocatalytic activity of multi-walled carbon nanotubes/Mgdoped $\mathrm{ZnO}$ nanohybrids. Mater Sci. 2015, 33, 460-469.

12. Hosseini, F.; Kasaeian, A.; Pourfayaz, F.; Sheikpour, M. Novel ZnO-Ag/MWCMT nanocomposite for the photocatalytic degradation of phenol. Mater. Sci. Semicond. Proc. 2018, $175-185$.

13. Kim, M.; Jo, W.K. Purification of aromatic hydrocarbons using a multiwalled carbon nanotube-ZnO nanocompositrs with high performnce. J. Indust. Eng. Chem. 2017, 47, 94101.

14. Moradi, M.; Haghighi, M.; Allahyari, S. Precipitation dispersion of Ag-ZnO nanocatalyst over functionalized multiwalled carbon nanotubes used in degradation of Acid Orange from waste water. Proc. Safety Environ. Protec. 2017, 107, 4141-427.

15. Xu, C.; Cao, L.; Su, G.; Liu, W.; Qu, X.; and Yu, Y. Preparation characterization and photocatalytic activity of Co-doped $\mathrm{ZnO}$ powders. J. Alloys Compd. 2010, 497, 373-376.

16. Hong, R.Y.; Li, J.H.; Chen, L.L.; Liu, D.Q.; Li, H.Z.; Zheng, Y.; Ding, J. Synthesis, surface modification and photocatalytic property of $\mathrm{ZnO}$ nanoparticles. Powder. Technol. 2009, 189, 426-432.

17. Chen, C.; Yu, B.; Liu, P.; Liu, J.F.; Wang, L. Ceramic processing research investigation of nano-sized $\mathrm{ZnO}$ particles fabricated by various synthesis routes. J. Ceram. Proc. Res. 2011, $12,420-425$. 
18. Kolen'ko, Y.; Churagulov, B.R.; Kunst, M.; Mazerolles, L.; Colbeau-Justin, C. Photocatalytic properties of titania powders prepared by hydrothermal method. Appl. Catal. B-Environ. 2004, 54, 51-58.

19. Gangu, K.K.; Maddila, S.; Jonnalagadda, S.B. A review on novel composites of MWCNTs mediated semiconducting materials as photocatalysts in water treatment. Sci. Total Environ. 2019, 646, 1398-1412.

20. Nejat, R.H.; Taddesse, A.M.; Ayalew, T. Synthesis,characterization and photocatalytic activity of $\mathrm{Mn}_{2} \mathrm{O}_{3} / \mathrm{Al}_{2} \mathrm{O}_{3} / \mathrm{Fe}_{2} \mathrm{O}_{3}$ nanocomposite for degradation of malachite green. Bull. Chem. Soc. Ethiop. 2018, 32, 101-109.

21. Patra, S.K. A novel chemical approach to fabricate $\mathrm{ZnO}$ nanostructure, MSc Thesis, Indian Institute of Technology, Kharagpur, 2007.

22. Sobana, N.; Muruganadham, M.; Swaminathan, M. Nano-Ag particles doped $\mathrm{TiO}_{2}$ for efficient photodegradation of direct azo dyes. J. Mol. Catal. A: Chem. 2006, 258, 124-132.

23. El-Kemary, M.; El-Shamy, H.; El-Mehasseb, I. Photocatalytic degradation of ciprofloxacin drug in water using $\mathrm{ZnO}$ nanoparticles. J. Lumin. 2010, 130, 2327-2331.

24. Shamsipura, M.; Pourmortazavi, S.M.; Hajimirsadeghi, S.S.; Zahedic, M.M.; RahimiNasrabadi, M. Facile synthesis of zinc carbonate and zinc oxide nanoparticles via direct carbonation and thermal decomposition. Ceram. Int. 2013, 39, 819-827.

25. Ahmed, F.; Shalendr, K.; Nishat, A.; Anwar, M.S.; Lee, S.Y.; Gyung-Suk, K.; Dae-Won, P.; Bon, H.K.; Chan, G.L. Preparation and characterizations of polyaniline (PANI)/ZnO nanocomposites film using solution casting method. Thin Solid Films. 2011, 519, 83758378.

26. Shaikshavalia, P.; Reddya, M.T.; Gopala, T.V.; Venkataprasada, G.; Kotakadib, V.S.; Palakollu, V.N.; Karpoormath, R. A simple sonochemical assisted synthesis of nanocomposite ( $\mathrm{ZnO} / \mathrm{MWCNTs}$ ) for electrochemical sensing of epinephrine in human serum and pharmaceutical formulation. Colloid Surf. A 2020, 584, 124038.

27. Patil, A.B.; Patil, K.R.; Pardeshia, S.K. Ecofriendly synthesis and solar photocatalytic ctivity of S-doped ZnO. J. Hazard. Mater. 2010, 183, 315-323.

28. Tesfay, W.; Yadav, O.P.; Taddesse, A.M.; Jyotsna, K. Synthesis, characterization and photocatalytic activities of $\mathrm{Ag}-\mathrm{N}$ codoped $\mathrm{ZnO}$ nanoparticles for degradation of methyl red. Bull. Chem. Soc. Ethiop. 2013, 27, 221-232.

29. Zhang, Y.; Mu J., One-pot synthesis, photoluminescence, and photocatalysis of Ag/ZnO composites. J. Colloid Interf. Sci. 2007, 309, 478-484.

30. Kongkanand, A.; Kamat, P.V. Electron storage in single wall carbon nanotubes. Fermi level equilibration in semiconductor-SWCNT suspension. ACS Nano 2007, 1, 13-21. 